\title{
EFFECTS OF LEADERSHIP STYLE ON ORGANIZATIONAL PERFORMANCE: A SURVEY OF SELECTED SMALL SCALE ENTERPRISES IN IKOSI-KETU COUNCIL DEVELOPMENT AREA OF LAGOS STATE, NIGERIA
}

\author{
Obiwuru Timothy C. \\ Department of Actuarial Science \\ University of Lagos, Nigeria
}

\author{
Okwu, Andy T. (Corresponding Author) \\ Department of Economics, Banking and Finance \\ Babcock University, Nigeria \\ E-mail:aokwu@yahoo.com
}

Akpa, Victoria 0.

Department of Business Administration and Marketing

Babcock University, Nigeria

Nwankwere, Idowu A.

Department of Business Administration and Marketing

Babcock University, Nigeria

\begin{abstract}
This study has investigated the effects of leadership style on organizational performance in small scale enterprises. The major objective was to determine effect of leadership styles on performance in small scale enterprises. Transformational and transactional leadership styles were considered in this study. Transformational leadership behaviours and performanceloutcome considered relevant in the study were charisma, inspirational motivation and intellectual stimulation/individual consideration; and effectiveness, extra effort and satisfaction, respectively. Transactional leadership bahaviours and performance/outcome variables were constructive/contingent reward and corrective/management by exception; and effort, productivity and loyalty/commitment, respectively. The study followed a survey design, and employed evaluative quantitative analysis method. Analysis was based on primary data generated through a structured Multifactor Leadership Questionnaire (MLQ) administered on respondents. Responses to research statements were scaled and converted to quantitative data via code manual developed for the study to enable segmentation of the data responses into dependent and independent variables based on leadership behaviours and associated performance variables. OLS multiple regression models were specified, estimated and evaluated. The result showed that while transactional leadership style had significant positive effect on performance, transformational leadership style had positive but insignificant effect on performance. The study concluded that transactional leadership style was more appropriate in inducing performance in small scale enterprises than transformational leadership style and, therefore, recommended transactional leadership style for the small enterprises with inbuilt strategies for transition to transformational leadership style as the enterprises developed, grew and matured.
\end{abstract}

Keywords: Leadership style, Effects, Performance, Small Scale Enterprise

\section{INTRODUCTION}

The concept and definition of leadership and style may differ from one person, or situation, to the other. The word 'leadership' has been used in various aspects of human endeavour such as politics, businesses, academics, social works, etc. Previous views about leadership show it as personal ability. Messick and Kramer (2004) argued that the degree to which the individual exhibits leadership traits depends not only on his characteristics and personal abilities, but also on the characteristics of the situation and environment in which he finds himself. Since human beings could become members of an organization in other to achieve certain personal objectives, the extent to which they are active members depends on how they are convinced that their membership will enable them to achieve their predetermined objectives. Therefore, an individual will support an organization if he believes that through it his personal objectives and goals could be met; if not, the person's interest will decline. Leadership style in an organization is one of the factors that play significant role in enhancing or retarding the interest and commitment of the individuals in the organization. Thus, Glantz (2002) emphasizes the need for a manager to find his leadership style. 
Among the objectives of any small enterprise are profit making and attainment of maturity and liquidity status. In the pursuit of these objectives, enterprises allocate scarce resources to competing ends. In the process they provide employment, provide goods and services, purchase goods and services and, thus, contribute to the growth of the society and economy at large. Unamaka (1995) observes that in most Nigerian small-scale settings, the effectiveness of this process is greatly determined by the availability of and access to personnel, finance, machinery, raw material and possibility of making their goods and services available to their immediate community and the nation at large.

The extent to which members of an organization contribute in harnessing the resources of the organization equally depends on how well the managers (leaders) of the organization understand and adopt appropriate leadership style in performing their roles as managers and leaders. Thus, efficiency in resources mobilization, allocation, utilization and enhancement of organizational performance depends, to a large extent, on leadership style, among other factors. Akpala (1998) identifies attitude to work, leadership style and motivation as some of the factors that exert negative effect on organizational performance in Nigeria.

Small and Medium Enterprise Development Agency of Nigeria (SMEDAN) in 2008, reports that most small and medium scale businesses in Nigeria die before their fifth anniversary. Ashibogwu (2008) notes that one of the reasons for this high failure is lack of use of market research to confirm demand and assess suitability of proposed offering as well as maintaining high level of customer patronage. Inappropriate leadership style could be one of the reasons for high failure of small enterprises.

The study aligns with the concept of leadership as explained by Taffinder (2006) and, thus, considers leadership within the context of a small-scale enterprise as the action of managers of the enterprise to contribute their best to the purpose of the enterprise. A small scale enterprise is one with relatively small number of employees and low capital strength. This study considers a small scale enterprise as one that has less than fifteen employees and whose capital outlay is less than three million naira.

From this consideration, this study is intended to evaluate the effect of leadership style on the performance of small enterprises, contribute to empirical studies on leadership style and business performance, proffer quantitative-based recommendations for policies and programmes to reposition the small scale enterprises at integral part of the engine of economic growth and development in Nigeria.

The study is divided into five sections. Section one is the introduction, section two is a review of related literature, section three discusses the methodology employed in carrying out the study, and section four is data presentation and analysis, while section five concludes the study and proffers recommendations for policy and entrepreneurial decisions.

\section{REVIEW OF RELATED LITERATURE}

\section{Leadership Style and Performance}

In the literature, leadership has been identified as an important subject in the field of organizational behaviour. Leadership is one with the most dynamic effects during individual and organizational interaction. In other words, ability of management to execute "collaborated effort" depends on leadership capability. Lee and Chuang (2009), explain that the excellent leader not only inspires subordinate's potential to enhance efficiency but also meets their requirements in the process of achieving organizational goals. Stogdill (1957), defined leadership as the individual behaviour to guide a group to achieve the common target. Fry (2003), explains leadership as use of leading strategy to offer inspiring motive and to enhance the staff's potential for growth and development. Several reasons indicate that there should be a relationship between leadership style and organizational performance. The first is that today's intensive and dynamic markets feature innovation-based competition, price/performance rivalry, decreasing returns, and the creative destruction of existing competencies (Santora et al., 1999; Venkataraman, 1997). Studies have suggested that effective leadership behaviours can facilitate the improvement of performance when organizations face these new challenges (McGrath and MacMillan, 2000; Teece, Pisano and Shuen, 1997).

On the other hand, organizational performance refers to ability of an enterprise to achieve such objectives as high profit, quality product, large market share, good financial results, and survival at pre-determined time using relevant strategy for action (Koontz and Donnell, 1993). Organizational performance can also be used to view how an enterprise is doing in terms of level of profit, market share and product quality in relation to other enterprises in the same industry. Consequently, it is a reflection of productivity of members of an enterprise measured in terms of revenue, profit, growth, development and expansion of the organization. 
Understanding the effects of leadership on performance is also important because leadership is viewed by some researchers as one of the key driving forces for improving a firm's performance. Effective leadership is seen as a potent source of management development and sustained competitive advantage for organizational performance improvement (Avolio, 1999; Lado, Boyd and Wright, 1992; Rowe, 2001). For instance, transactional leadership helps organizations achieve their current objectives more efficiently by linking job performance to valued rewards and by ensuring that employees have the resources needed to get the job done (Zhu, Chew and Spengler, 2005). Visionary leaders create a strategic vision of some future state, communicate that vision through framing and use of metaphor, model the vision by acting consistently, and build commitment towards the vision (Avolio, 1999; McShane and Von Glinow, 2000). Some scholars like Zhu et al. (2005), suggest that visionary leadership will result in high levels of cohesion, commitment, trust, motivation, and hence performance in the new organizational environments.

Mehra, Smith, Dixon and Robertson (2006) argue that when some organizations seek efficient ways to enable them outperform others, a longstanding approach is to focus on the effects of leadership. Team leaders are believed to play a pivotal role in shaping collective norms, helping teams cope with their environments, and coordinating collective action. This leader-centred perspective has provided valuable insights into the relationship between leadership and team performance (Guzzo and Dickson, 1996). Some studies have explored the strategic role of leadership to investigate how to employ leadership paradigms and use leadership behaviour to improve organizational performance (Judge, Bono, Ilies, and Gerhardt, 2002; Judge and Piccolo, 2004; Keller, 2006; McGrath and MacMillan, 2000; Meyer and Heppard, 2000; Purcell, Kinnie, Hutchinson and Dickson, 2004; Yukl, 2002). This is because intangible assets such as leadership styles, culture, skill and competence, and motivation are seen increasingly as key sources of strength in those firms that can combine people and processes and organizational performance (Purcell et al., 2004).

Previous studies led the expectation that leadership paradigms will have direct effects on customer satisfaction, staff satisfaction, and financial performance. In general, however, the effects of leadership on organizational performance have not been well studied, according to House and Aditya's review (1997), who criticised leadership studies for focusing excessively on superior-subordinate relationships to the exclusion of several other functions that leaders perform, and to the exclusion of organizational and environmental variables that are crucial to mediate the leadership-performance relationship. Another problem with existing studies on leadership is that the results depend on the level of analysis. House and Aditya (1997), distinguished between micro-level research that focuses on the leader in relation to the subordinates and immediate superiors, and macro-level research that focuses on the total organization and its environment. Other scholars have also suggested that leaders and their leadership style influence both their subordinates and organizational outcomes (Tarabishy, Solomon, Fernald, and Sashkin, 2005).

Fenwick and Gayle (2008), in their study of the missing links in understanding the relationship between leadership and organizational performance conclude that despite a hypothesised leadership-performance relationship suggested by some researchers, current findings are inconclusive and difficult to interpret.

From this review of related literature, it is evident that although some scholars believe that leadership enhances organizational performance while others contradict this, different concepts of leadership have been employed in different studies, making direct comparisons virtually impossible. Gaps and unanswered questions remain. Consequently, the current study is intended to re-examine the proposed leadership-performance relationship and, thus, contribute meaningfully to the body of growing literature and knowledge in this area of study.

\section{Theories of Leadership}

Among the various theories of leadership and motivation relating to effective organizational change management, perhaps the most prominent is the transformational-transactional theory of leadership. As explained in Saowalux and Peng (2007), Burns (1978), conceptualizes two factors to differentiate "ordinary" from "extraordinary" leadership: transactional and transformational leadership. Transactional leadership is based on conventional exchange relationship in which followers' compliance (effort, productivity, and loyalty) is exchanged for expected rewards. In contrast, transformational (extraordinary) leaders raise followers' consciousness levels about the importance and value of designated outcomes and ways of achieving them. They also motivate followers to transcend their own immediate self-interest for the sake of the mission and vision of the organization.

Such total engagement (emotional, intellectual and moral) encourages followers to develop and perform beyond expectations (Burns, 1978; Bass, 1985). Burns (1978), observes that transformational leadership involves the process of influencing major changes in organizational attitudes in order to achieve the organization's objectives 
and strategies. Bass (1985), observed that transactional leaders work their organizational cultures following existing rules and procedures, while transformational leaders change their cultures based on a new vision and a revision of shared assumptions, values and norms. When an organization must adapt to changes in technology, its leadership is a critical factor in its successful change.

Bass (1985), operationalized the work of Burns (1978) by developing a model of transformational and transactional leadership, referred to in more recent publications as the "full range leadership model" (Bass and Avolio, 1997).

\section{Transformational Leadership}

The difference between transformational and transactional leadership lies in the way of motivating others. A transformational leader's behaviour originates in the personal values and beliefs of the leader and motivates subordinates to do more than expected (Bass, 1985). Burns (1978), identified transformational leadership as a process where, "one or more persons engage with others in such a way that leaders and followers raise one another to higher levels of motivation and morality".

For transformational leadership style, the follower feels trust, admiration, loyalty and respect towards the leader, and is motivated to do more than what was originally expected to do (Bass, 1985; Katz \& Kahn, 1978). The transformational leader motivates by making follower more aware of the importance of task outcomes, inducing them to transcend their own self-interest for the sake of the organization or team and activating their higherorder needs. He encourages followers to think critically and seek new ways to approach their jobs, resulting in intellectual stimulation (Bass et al., 1994). As a result, there is an increase in their level of performance, satisfaction, and commitment to the goals of their organization (Podsakoff et al, 1996).

Bass (1990), proposed four behaviours or components of transformational leadership to include charisma, inspirational motivation, intellectual stimulation, and individual consideration.

Charisma, or idealized influence or attributes, is characterized by vision and a sense of mission, instilling pride in and among the group, and gaining respect and trust (Humphreys \& Einstein, 2003). Charismatic behaviour also induces followers to go beyond self-interest for the good of the group, providing reassurance that obstacles will be overcome, and promoting confidence in the achievement and execution influence (Conger and Kanungo, 1998; Howell and Frost, 1989) and followers place an inordinate amount of confidence and trust in charismatic leaders (Howell and Avolio, 1992).

Inspirational motivation is usually a companion of charisma and is concerned with a leader setting higher standards, thus becoming a sign of reference. Bass (1985), points out followers look up to their inspirational leader as one providing emotional appeal to increase awareness and understanding of mutually desirable goals. This is characterized by the communication of high expectations, using symbols to focus efforts, and expressing important purpose in simple ways. The leader always behaves talking optimistically about the future, articulating a compelling vision for the future and providing an exciting image of organizational change (Bass and Avolio, 1994). The motivation occurs by providing meaning and challenge to the followers' work; individual and team spirit are aroused and. enthusiasm and optimism are displayed. The leader encourages followers to envision attractive future states, for the organization and themselves (Bass et al, 1997).

Intellectual stimulation provides followers with challenging new ideas and encourages them to break away from the old ways of thinking (Bass, 1985). The leader is characterized as one promoting intelligence, rationality, logical thinking, and careful problem solving. The attributes include seeking differing perspectives when solving problems, suggesting new ways of examining how to complete assignments and encouraging re-thinking of ideas that have not been questioned in the past (Bass and Avolio, 1994). The leader encourages the followers to be innovative and creative by questioning assumptions, reframing problems, and approaching old situations in new ways.

Finally, the fourth dimension of transformational leadership is "individual consideration" which is concerned with developing followers by coaching and mentoring (Bass, 1985; Bass \& Avolio, 1990). The leader pays close attention to the inter-individual differences among the followers and act as mentor to the follower. He teaches and helps others develop their strengths, and listens attentively to others' concerns (Bass and Avolio, 1994). Followers are treated individually in order to raise their levels of maturity and to enhance effective ways of addressing their goals and challenges (Bass, 1985). 


\section{Transactional Leadership}

Transactional leadership involves an exchange process that results in follower compliance with leader request but not likely to generate enthusiasm and commitment to task objective. The leader focuses on having internal actors perform the tasks required for the organization to reach its desired goals (Boehnke et al, 2003). The objective of the transactional leader is to ensure that the path to goal attainment is clearly understood by the internal actors, to remove potential barrier within the system, and to motivate the actors to achieve the predetermined goals (House and Aditya, 1997).

Transactional leaders display both constructive and corrective behaviours. Constructive behaviour entails contingent reward, and corrective dimension imbibes management by exception. Contingent reward involves the clarification of the work required to obtain rewards and the use of incentives and contingent reward to exert influence. It considers follower expectations and offers recognition when goals are achieved. The clarification of goals and objectives and providing of recognition once goals are achieved should result in individuals and groups achieving expected levels of performance (Bass, 1985). Active management by exception refers to the leader setting the standards for compliance as well as for what constitutes ineffective performance, and may include punishing followers for non-compliance with those standards. This style of leadership implies close monitoring for deviances, mistakes, and errors and then taking corrective action as quickly as possible when they occur.

\section{METHODOLOGY}

This research follows a survey design, and analysis is based on primary data generated through a structured questionnaire administered on respondents. Survey instrument used in data generation is the Multifactor Leadership Questionnaire (MLQ) developed by Bass (1985) in his study: 'Leadership and Performance beyond Expectations'. This instrument is by far the most widely used instrument for measuring leadership styles and outcomes or effects. It comes in several different versions. The version used in this study is the popular MLQ Form 5x-Short. The independent variables are the transformational and transactional leadership styles, while the dependent variables are the outcomes: extra effort, effectiveness and satisfaction (as disaggregate performance measures of transformational leadership behaviour); effort, productivity and loyalty (as disaggregated performance measures of transactional leadership behaviour) in the selected small scale enterprises. Therefore, questions in the questionnaire are those relating to leadership styles or behavoiurs and performance as measured by extra effort, effectiveness and satisfaction; effort, productivity and loyalty/commitment. These variables are as proposed by Bass (1990) and House et al (1997). This study operationalizes these variables to evaluate the effect of leadership style or behavior on performance of small scale enterprises in the survey area. In the MLQ, each independent variable is given equal weighting. Each research statement has five potential responses, ranging from "not at all" to "all the times" and is scaled from 0 to 4.

Three small-scale enterprises were initially selected through stratified random sampling technique, from a total of 18 subjectively identified small scale enterprises in area. The enterprises were stratified according to their respective industries or activities - water packaging, restaurant/food canteen services, and wood finish production. Five respondents were randomly selected from each of these three enterprises for a sample size of fifteen (15) respondents. A pilot test conducted on the sample showed that leadership style in two was transactional, while leadership style in the third enterprise was transformational style. Since none was laissezfaire leadership style, the study concentrated on the two leadership styles, and sample size was reduced to ten.

Copies of the questionnaire were distributed to the respondents with instructions on how to fill them out. Altogether, 10 survey forms were distributed, all were returned filled out, giving a return rate of $100 \%$. The reason for the high return rate was that the researcher personally visited the enterprises, explained and convinced the participants on the purpose of the research and the need for participation.

Correlations and ordinary least squares (OLS) multiple regression analysis models were used to analyze the hypotheses regarding the relationship between the respective leadership styles and each of the performance measures of the small scale enterprises. The OLS fits multiple response variables in a single model that captures the responses in a multivariate way such that results may differ significantly from those calculated for the responses individually. The hypotheses are analyzed via evaluation of relevant statistics associated with the numerical values of model parameters vis-à-vis their critical values contained in the tables.

\section{Research Hypotheses}

The exploit in this study progresses from the propositions that there is no relationship between leadership style and performance, and that the respective leadership styles does not exert significant effect on performance in the small scale enterprises. Hence, the first hypothesis relates to relationship between leadership style and 
performance in the enterprises, while the second and third relate to effects of transformational and transactional leadership styles on follower/organizational performance.

Cause and Effect Relationship, Model Specification and Correlation Coefficient

The multiple regression model of the functional relationship between leadership style and performance facilitates evaluation of effect of leadership style on organizational performance.

\section{Function Relationship}

From the perceived relationship between leadership style and performance, functional relationships and associated multiple regression models were specified for transformational and transactional leadership styles, respectively.

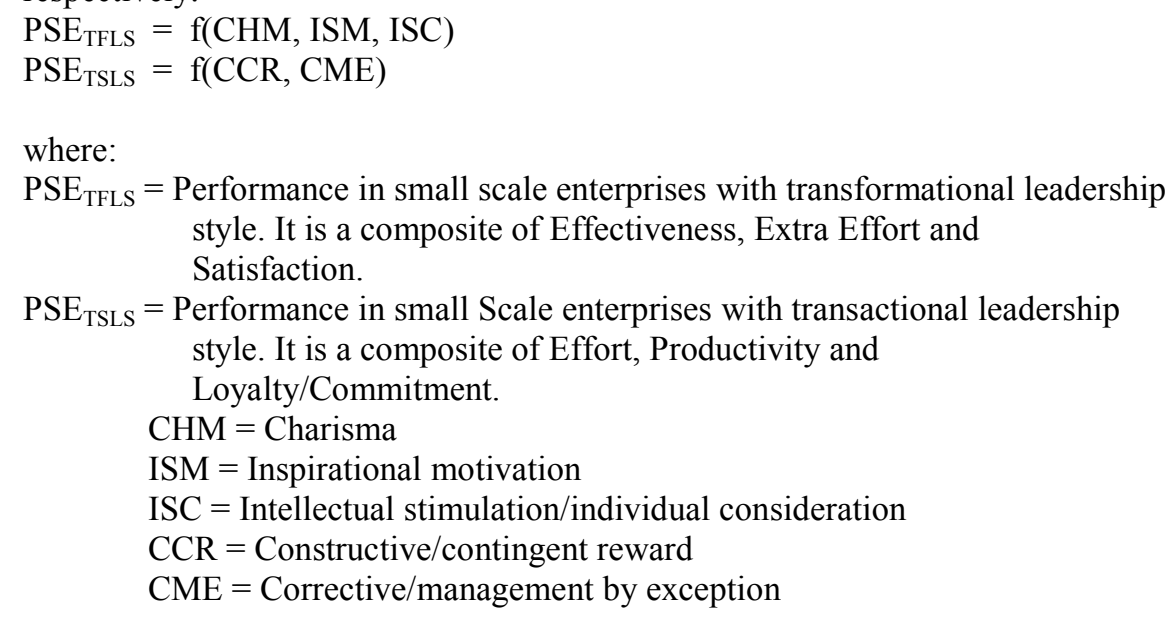

\section{Models}

$\mathrm{PSE}_{\mathrm{TFLS}}=\alpha_{0}+\alpha_{1} \mathrm{CHM}+\alpha_{2} \mathrm{ISM}+\alpha_{3} \mathrm{ISC}+\mu$

$\mathrm{PSE}_{\mathrm{TSLS}}=\beta_{0}+\beta_{1} \mathrm{CCR}+\beta_{2} \mathrm{CME}+\mu$

where $\alpha_{0}$ and $\beta_{0}$ are constants, which denote performance of small scale enterprises that is independent of the respective leadership styles, $\alpha_{1}, \alpha_{2}$, and $\alpha_{3} ; \beta_{1}, \beta_{2}$ and $\beta_{3}$ are model coefficients denoting the effect of the respective leadership behaviours on organizational performance.

$\mu$ is a random variable introduced to accommodate effect of other factors that affect organizational performance within or outside the leadership behaviours that are not included in the model.

\section{Expectations}

On estimation, each of the model parameters is expected to be positive. That is, $\alpha_{i}(i=0,1,2,3)>0 ; \beta_{i}(i=0,1,2,3)>$,0 , implying that the respective leadership behaviours are expected, a priori, to exert positive effect on performance.

\section{Correlation Coefficient (r)}

This coefficient indicates the nature and extent of the relationship between leadership style or behavoiur and performance of the enterprises. Its numerical value ranges from -1 to $+1(-1 \leq \mathrm{r} \leq+1)$. In this study, it is derived as the square root of coefficient of multiple determination (R-Squared) in the regression output. -1 implies perfect negative correlation or relationship. +1 implies perfect positive correlation or relationship. Other degrees of correlation or relationship are interpreted according to how close or far away from the two extreme values.

A code manual developed from the code guide was used to convert the respondents' responses to quantitative data and regressible functions. Responses on leadership style performance outcome constituted the dependent variable, while the responses on the various leadership behaviours constituted the independent variables. These two sets of variables were expressed in functional relationships and multiple linear regression models whose parameters/coefficients were estimated, discussed and evaluated to operationalized and test the research hypotheses. The OLS technique was used to estimate numerical values of models parameters/coefficients and obtain relevant statistics for further analysis and evaluation. Estimation is facilitated with the software statistical package - Econometric Views (E-Views). 
4. DATA ANALYSIS AND DISCUSSION OF RESULTS

Table 1: Responses on Leadership Behaviours - Transformational Leadership Style

\begin{tabular}{|c|c|c|c|c|c|c|c|c|c|c|c|c|c|c|c|c|c|c|c|}
\hline & \multicolumn{6}{|c|}{ Charisma } & \multicolumn{6}{|c|}{ Inspirational Motivation } & \multicolumn{6}{|c|}{$\begin{array}{c}\text { Intellectual Stimulation/Individual } \\
\text { Consideration }\end{array}$} & \multirow[b]{2}{*}{ IAV } \\
\hline $\mathbf{R} / \mathbf{S}$ & S1 & S2 & S3 & S4 & S5 & AV & S6 & S7 & S8 & S9 & S10 & AV & S11 & S12 & S13 & S14 & S15 & AV & \\
\hline R1 & 4 & 3 & 4 & 4 & 3 & 3.6 & 4 & 4 & 3 & 4 & 3 & 3.6 & 3 & 3 & 3 & 4 & 4 & 3.4 & 3.5 \\
\hline $\mathbf{R 3}$ & 3 & 4 & 4 & 3 & 3 & 3.4 & 4 & 4 & 2 & 4 & 3 & 3.4 & 3 & 4 & 3 & 3 & 4 & 3.4 & 3.4 \\
\hline $\mathbf{R 4}$ & 3 & 4 & 4 & 4 & 3 & 3.6 & 2 & 2 & 3 & 4 & 4 & 3.0 & 3 & 4 & 3 & 4 & 3 & 3.4 & 3.3 \\
\hline R5 & 3 & 4 & 4 & 4 & 4 & 3.8 & 4 & 4 & 4 & 4 & 4 & 4.0 & 4 & 4 & 3 & 4 & 3 & 3.6 & 3.8 \\
\hline R7 & 4 & 4 & 3 & 3 & 4 & 3.6 & 4 & 4 & 4 & 3 & 3 & 3.6 & 4 & 2 & 4 & 4 & 4 & 3.6 & 3.6 \\
\hline R8 & 4 & 4 & 4 & 3 & 3 & 3.6 & 3 & 4 & 4 & 2 & 2 & 3.0 & 4 & 4 & 4 & 4 & 3 & 3.8 & 3.5 \\
\hline R9 & 4 & 4 & 4 & 3 & 3 & 3.6 & 3 & 4 & 3 & 3 & 2 & 3.0 & 4 & 4 & 4 & 4 & 3 & 3.8 & 3.5 \\
\hline \multirow[t]{2}{*}{ R10 } & 4 & 4 & 4 & 4 & 4 & 4.0 & 4 & 3 & 3 & 4 & 4 & 3.6 & 3 & 3 & 3 & 4 & 2 & 3.0 & 3.5 \\
\hline & \multicolumn{5}{|c|}{ Average of Averages } & 3.6 & \multicolumn{6}{|c|}{ Average of Averages } & \multicolumn{5}{|c|}{ Average of Averages } & 3.4 & $3.5^{*}$ \\
\hline
\end{tabular}

Note: $\mathrm{Ri}=$ Respondent $\mathrm{i}(\mathrm{i}=1,2,3,---10) ; \mathrm{Si}=$ Statement $\mathrm{i}(\mathrm{I}=1,2,3,---, 15) ; \mathrm{AV}=$ Average response on charismatic, inspirational and intellectual behaviours, respectively; IAV = Individual respondents' average response on transformational leadership style traits. * Overall Average response on the traits; IAV = Individual Average

Source: Computed from Code Manuel

Table1 shows that each of the respondents agrees that, on the average, the leadership behaviour is charismatic and inspirationally motivating most of the time. But while other respondents agree that, on the average, the leadership behaviour also stimulates intellectually and considers followers on individual basis most of the time, respondent number two (R2) was of the opinion that those behaviours were exhibited only some times. However, on overall average, all respondents were of the view that leadership style in their enterprise exhibited these three behaviours - charisma, inspirational motivation and intellectual stimulation/individual consideration - most of the time. This shows that the leadership style in this organization exhibits transformational behaviours.

Table 2: Responses on Leadership Behaviours - Transactional Leadership Style

\begin{tabular}{|c|c|c|c|c|c|c|c|c|c|c|c|c|c|c|c|c|c|c|}
\hline & \multicolumn{9}{|c|}{ Constructive/Contingent Reward } & \multicolumn{8}{|c|}{ Corrective/Management by Exception } & \multirow[b]{2}{*}{ IAV } \\
\hline $\mathbf{R} / \mathbf{S}$ & S1 & $\mathbf{S 2}$ & S3 & S4 & S5 & S6 & S7 & S8 & $\mathbf{A V}$ & S9 & S10 & S11 & S12 & S13 & S14 & S15 & $\mathbf{A V}$ & \\
\hline R1 & 4 & 4 & 2 & 3 & 4 & 4 & 3 & 4 & 3.5 & 4 & 4 & 4 & 4 & 4 & 3 & 4 & 3.9 & 3.7 \\
\hline $\mathbf{R 2}$ & 4 & 4 & 4 & 3 & 3 & 4 & 4 & 4 & 3.8 & 3 & 3 & 3 & 4 & 2 & 4 & 3 & 3.1 & 3.5 \\
\hline R3 & 4 & 3 & 4 & 3 & 4 & 4 & 3 & 4 & 3.6 & 4 & 3 & 4 & 4 & 3 & 4 & 4 & 3.7 & 3.7 \\
\hline R4 & 4 & 4 & 4 & 3 & 4 & 3 & 4 & 4 & 3.8 & 4 & 4 & 4 & 4 & 3 & 4 & 4 & 3.9 & 3.9 \\
\hline R5 & 4 & 4 & 3 & 4 & 4 & 4 & 4 & 4 & 3.9 & 4 & 4 & 3 & 4 & 4 & 4 & 4 & 3.9 & 3.9 \\
\hline R6 & 4 & 4 & 4 & 3 & 4 & 4 & 4 & 3 & 3.8 & 3 & 3 & 4 & 4 & 4 & 3 & 4 & 3.6 & 3.7 \\
\hline R7 & 4 & 4 & 4 & 3 & 3 & 4 & 4 & 3 & 3.6 & 3 & 4 & 4 & 4 & 3 & 3 & 4 & 3.6 & 3.6 \\
\hline R8 & 4 & 3 & 3 & 3 & 4 & 4 & 4 & 4 & 3.6 & 4 & 4 & 4 & 4 & 3 & 3 & 4 & 3.7 & 3.7 \\
\hline R9 & 4 & 4 & 4 & 3 & 4 & 4 & 3 & 4 & 3.8 & 4 & 4 & 4 & 4 & 4 & 4 & 4 & 4.0 & 3.9 \\
\hline R10 & 4 & 4 & 4 & 3 & 3 & 4 & 4 & 4 & 3.8 & 3 & 3 & 4 & 3 & 4 & 4 & 4 & 3.4 & 3.6 \\
\hline & & & & age & $\mathrm{Avv}$ & ages & & & 3.7 & & & Aver & ge of & vera & & & 3.7 & $3.7 *$ \\
\hline
\end{tabular}

Note: $\mathrm{Ri}=$ Respondent $\mathrm{i}(\mathrm{i}=1,2,3,---10) ; \mathrm{Si}=$ Statement $\mathrm{i}(\mathrm{i}=1,2,3,---, 15)$;

$\mathrm{AV}=$ Average response on constructive and corrective behaviours respectively;

$\mathrm{IAV}=$ Individual respondents' average response on the behaviours; * Overall Average.

Source: Computed from Code Manual

Table 2 shows that each of the respondents agrees that, on the average, the leadership exhibits constructive or contingent reward behaviour most of the time. While other respondents also agree that, on the average, the behaviour is equally corrective or management by exception, one respondent (R9) expresses the view that the behaviour is corrective or management by exception all the time. However, all respondents agree that the leadership displays constructive or contingent and corrective or management by exception behaviour most of the time. Therefore, it can be concluded that the leadership style is transactional. 
Table 3: Responses on Performance/Outcome - Transformational Leadership Style

\begin{tabular}{|c|c|c|c|c|c|c|c|c|c|c|c|c|c|c|c|c|c|c|c|}
\hline & \multicolumn{6}{|c|}{ Effectiveness } & \multicolumn{6}{|c|}{ Extra Effort } & \multicolumn{6}{|c|}{ Satisfaction } & \multirow[b]{2}{*}{ IAV } \\
\hline $\mathrm{R} / \mathrm{S}$ & S1 & $\mathrm{S} 2$ & S3 & S4 & S5 & $\mathbf{A V}$ & S6 & S7 & S8 & S9 & $\mathrm{S} 10$ & $\mathbf{A V}$ & S11 & S12 & S13 & S14 & S15 & $\mathbf{A V}$ & \\
\hline R1 & 4 & 4 & 3 & 3 & 4 & 3.6 & 3 & 3 & 3 & 3 & 4 & 3.2 & 3 & 3 & 2 & 3 & 4 & $\mathbf{3 . 0}$ & 3.3 \\
\hline $\mathbf{R 2}$ & 4 & 4 & 4 & 4 & 2 & 3.6 & 4 & 3 & 4 & 3 & 4 & 3.6 & 3 & 4 & 2 & 4 & 3 & 3.2 & 3.5 \\
\hline R3 & 4 & 3 & 4 & 3 & 3 & 3.4 & 4 & 3 & 2 & 4 & 2 & 3.0 & 4 & 4 & 3 & 4 & 4 & 3.8 & 3.4 \\
\hline R4 & 4 & 4 & 4 & 3 & 4 & 3.8 & 3 & 4 & 4 & 4 & 3 & 3.6 & 4 & 4 & 3 & 2 & 4 & 3.4 & 3.6 \\
\hline R5 & 3 & 3 & 3 & 4 & 3 & 3.2 & 4 & 4 & 2 & 4 & 4 & 3.6 & 3 & 3 & 4 & 4 & 4 & 3.6 & 3.5 \\
\hline R6 & 4 & 4 & 4 & 3 & 4 & 3.8 & 4 & 3 & 3 & 2 & 3 & 3.0 & 4 & 4 & 4 & 3 & 4 & 3.8 & 3.5 \\
\hline R7 & 4 & 3 & 4 & 4 & 3 & 3.6 & 4 & 4 & 4 & 3 & 4 & 3.8 & 4 & 4 & 2 & 3 & 4 & 3.4 & 3.6 \\
\hline R8 & 4 & 3 & 4 & 3 & 4 & 3.6 & 4 & 4 & 3 & 4 & 4 & 3.8 & 4 & 3 & 3 & 3 & 4 & 3.4 & 3.6 \\
\hline R9 & 4 & 4 & 4 & 3 & 4 & 3.8 & 4 & 3 & 4 & 4 & 4 & 3.8 & 2 & 4 & 3 & 4 & 4 & 3.4 & 3.7 \\
\hline R10 & 4 & 4 & 3 & 4 & 3 & 3.6 & 4 & 4 & 2 & 3 & 3 & 3.2 & 4 & 3 & 4 & 4 & 4 & 3.8 & 3.5 \\
\hline & & Ave & e of & vera & & .6 & & $\overline{\text { vera }}$ & of & arag & & & & Ivera & of $\mathrm{Av}$ & ages & 3.4 & & $3.5^{*}$ \\
\hline
\end{tabular}

Note: $\mathrm{Ri}=$ Respondent i $(\mathrm{i}=1,2,3,--$ - 10); $\mathrm{Si}=$ Statement i $(\mathrm{I}=1,2,3,---, 15)$;

$\mathrm{AV}=$ Average response on the respective transformational performance measures;

IAV = Individual respondents' average response on performance; * Overall Average.

Source: Computed from Code Manual

It is evident from Table 3 that each respondent agrees that, on the average, transformational leadership style enhances effectiveness, extra effort and satisfaction on the followers most of the time. Similarly, all respondents agree that, on the average, the style induces the same outcomes on the followers. Therefore, it can be concluded that transformational leadership style induces effectiveness, extra effort and satisfaction in the followers or employees.

Table 4: Responses on Performance/Outcome - Transactional Leadership Style

\begin{tabular}{|c|c|c|c|c|c|c|c|c|c|c|c|c|c|c|c|c|c|c|c|}
\hline & \multicolumn{6}{|c|}{ Effort } & \multicolumn{6}{|c|}{ Productivity } & \multicolumn{6}{|c|}{ Loyalty/Commitment } & \multirow[b]{2}{*}{ IAV } \\
\hline $\mathrm{R} / \mathrm{S}$ & S1 & S2 & S3 & S4 & S5 & $\mathbf{A V}$ & S6 & S7 & S8 & S9 & S10 & $\mathbf{A V}$ & S11 & S12 & S13 & S14 & S15 & $\mathbf{A V}$ & \\
\hline R1 & 2 & 2 & 2 & 3 & 3 & 2.4 & 2 & 3 & 2 & 3 & 0 & 2.0 & 1 & 2 & 0 & 3 & 4 & 2.0 & 2.1 \\
\hline $\mathbf{R 2}$ & 3 & 2 & 2 & 2 & 2 & 2.2 & 2 & 3 & 2 & 2 & 1 & 2.0 & 1 & 2 & 0 & 3 & 3 & 1.8 & 2.0 \\
\hline R3 & 3 & 3 & 3 & 2 & 2 & 2.6 & 3 & 3 & 3 & 2 & 1 & 2.4 & 2 & 2 & 1 & 3 & 3 & 2.2 & 2.4 \\
\hline R4 & 2 & 2 & 3 & 2 & 2 & 2.2 & 2 & 3 & 2 & 1 & 2 & 2.0 & 1 & 2 & 2 & 3 & 3 & 2.2 & 2.1 \\
\hline R5 & 3 & 2 & 3 & 2 & 2 & 2.4 & 3 & 2 & 1 & 1 & 0 & 1.4 & 3 & 2 & 0 & 3 & 4 & 2.4 & 2.1 \\
\hline R6 & 2 & 3 & 2 & 3 & 3 & 2.6 & 2 & 3 & 2 & 2 & 2 & 2.2 & 1 & 1 & 1 & 3 & 3 & 1.8 & 2.2 \\
\hline R7 & 4 & 2 & 3 & 3 & 2 & 2.8 & 2 & 3 & 0 & 2 & 1 & 1.6 & 0 & 2 & 2 & 2 & 4 & 2.0 & 2.1 \\
\hline R8 & 3 & 3 & 3 & 2 & 1 & 2.4 & 3 & 3 & 2 & 1 & 1 & 2.0 & 1 & 0 & 2 & 3 & 4 & 2.0 & 2.1 \\
\hline R9 & 2 & 4 & 2 & 4 & 3 & 3.0 & 3 & 2 & 1 & 2 & 3 & 1.8 & 2 & 2 & 0 & 2 & 3 & 1.8 & 2.2 \\
\hline R10 & 3 & 3 & 3 & 3 & 3 & $\mathbf{3 . 0}$ & 2 & 3 & 3 & 3 & 2 & 2.6 & 2 & 2 & 2 & 3 & 4 & 2.6 & 2.7 \\
\hline & & rag & of $\mathrm{Al}$ & age & 2.56 & & & rage & Av & ges & 2. & & & age 0 & Aver: & & 2.08 & & 2.21 \\
\hline
\end{tabular}

Note: $\mathrm{Ri}=$ Respondent i $(\mathrm{i}=1,2,3,---10) ; \mathrm{Si}=$ Statement $\mathrm{i}(\mathrm{I}=1,2,3,---, 15)$;

$\mathrm{AV}=$ Average response on the respective transactional leadership performance measures;

IAV = Individual respondents' average response on transactional performance measures;

* Overall Average.

Source: Code Manual

Table 4 shows that eight respondents (R1 to R8) agree that, on the average, transactional leadership style sometimes induces effort, while two respondents (R9 and R10) believe that, on the average, the style induces effort most of the time. Similarly, seven respondents (R1 to R4, R6, R8 and R10) agree that, on the average, the style sometimes promotes productivity, and three respondents (R5, R7 and R9) agree that, on the average, the style enhances productivity on rare occasions. Further, seven respondents (R1, R3 to R5, R7 to R8 and R10) are of the view that transactional leadership style sometimes promotes loyalty/commitment, while three respondents (R2, R6 and R9) expressed the view that, on the average, the style rarely promotes loyalty/commitment. Therefore, it can be concluded that transactional leadership style sometimes promotes effort, productivity and loyalty/commitment. 


\section{Effect of Leadership Style on Performance}

To determine the relationship between leadership style and organizational performance, and subsequently evaluate the effect of leadership style on performance, average performance response variables are regressed on leadership behaviour variables shown in Table E below.

Table 5: Average Leadership Behaviour and Performance Measure Variables

\begin{tabular}{|c|c|c|c|c|c|c|}
\hline PSE $_{\text {TFLS }}$ & CHM & ISM & ISC & PSE $_{\text {TSLS }}$ & CCR & CME \\
\hline 3.3 & 3.6 & 3.6 & 3.4 & 3.7 & 3.5 & 3.9 \\
\hline 3.5 & 3.6 & 3.4 & 2.6 & 3.5 & 3.8 & 3.1 \\
\hline 3.4 & 3.4 & 3.4 & 3.4 & 3.7 & 3.6 & 3.7 \\
\hline 3.6 & 3.6 & 3.0 & 3.4 & 3.9 & 3.8 & 3.9 \\
\hline 3.5 & 3.8 & 4.0 & 3.6 & 3.9 & 3.9 & 3.9 \\
\hline 3.5 & 3.6 & 3.2 & 3.4 & 3.7 & 3.8 & 3.6 \\
\hline 3.6 & 3.6 & 3.6 & 3.6 & 3.6 & 3.6 & 3.6 \\
\hline 3.6 & 3.6 & 3.0 & 3.8 & 3.7 & 3.6 & 3.7 \\
\hline 3.7 & 3.6 & 3.0 & 3.8 & 3.9 & 3.8 & 4.0 \\
\hline 3.5 & 4.0 & 3.6 & 3.0 & 3.6 & 3.8 & 3 \\
\hline
\end{tabular}

Source: Tables $A-D$

Estimated Models and Discussion

$\mathrm{PSE}_{\mathrm{TFLS}}=2.766268+0.310436 \mathrm{CHM}-0.216371 \mathrm{ISM}+0.104436 \mathrm{ISC}$

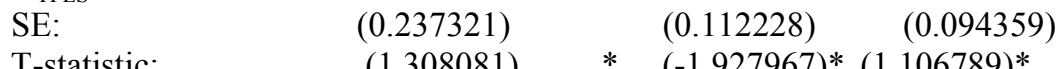

T-statistic: $\quad(1.308081) \quad * \quad(-1.927967) *(1.106789) *$

Prob(t-stat) (0.2387) (0.1021) (0.3108)

$\mathrm{R}^{2}=0.486445 \quad$ F-statistic $=1.894423 * *$

*Insignificant at 5\%,**Significant at 5\%

Source: Regression Output

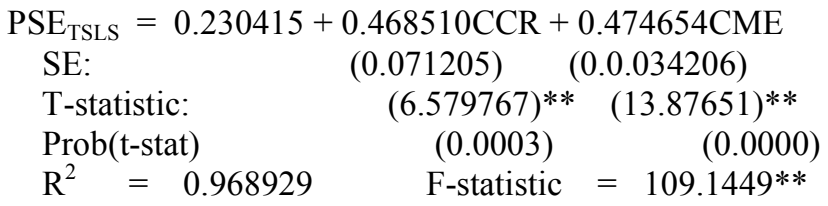

**Significant at 5\%

Source: Regression Output

The estimated models show that the coefficients are consistent with expectations, except for inspirational motivation (ISM). These show that while the other leadership behaviours have positive effect on performance, ISM has negative effect. However, at the 5\% level of significance, while the respective partial effects as well as joint effect of transformational leadership behaviours on performance are statistically insignificant, those of transactional leadership behaviours on performance are significant. The coefficients of determination $\left(\mathrm{R}^{2}=\right.$ 0.486445 and $\mathrm{R}^{2}=0.968929$ ) show the relative importance of the two leadership styles in explaining organizational performance in the surveyed small scale enterprises. These model explanatory powers show that transactional leadership style bears more relevance in explaining performance in small scale enterprises than transformational leadership style. The square roots of these coefficients $(\mathrm{R}=0.697456$ and $\mathrm{R}=0.984342)$ indicate differing degrees of positive correlation between performance and leadership styles. That is, in the surveyed small scale enterprises, performance is more positively correlated with transactional leadership style than transformational leadership style.

Consequently, it can be concluded that in that in the small scale enterprises, while transactional leadership style has significant positive effect on performance, the effect of transformational leadership style on performance is insignificant. A possible reason for this is that the employees of small scale enterprises are usually not skilled and experienced professionals. Therefore, contingent recognition/reward and management by exception rather than charisma, inspirational motivation and intellectual stimulation/individual consideration could be appropriate leadership behaviours and strategies to induce them to perform.

\section{CONCLUSION AND RECOMMENDATIONS}

This study has evaluated the effect of leadership styles on organizational performance in selected small scale enterprises. The analysis has shown that each of charisma and intellectual stimulation/individual consideration traits of transformational leadership style exerts positive but insignificant effect on followers and performance. The other trait, inspirational motivation, exerts negative but insignificant effect on performance, and. The traits 
are weak in explaining variations in performance. On the other hand, each trait of transactional leadership style considered in this study, constructive/contingent reward and corrective and management by exception has significant positive effect on followers and performance, and both jointly explain very high proportion of variations in performance. The study concludes that transactional leadership style is more appropriate in inducing performance in small scale enterprises than transformational leadership style. Consequently, the study recommends that small scale enterprises should adopt transactional leadership style but strategise to transit to transformational leadership style as their enterprises develop, grow and mature.

\section{REFERENCES}

3. Akpala, A. (1998). Igbo Cultural Factors that may bear on Management and Organizational Performance in Nigeria. In Imaga, E. U. L. \& Ewurum, U. J. F. (eds.) Business Management Topics, Vol. 1. Enugu, Oktek publishers.

4. Ashibogwu, M. (2008). Common Failures of Family Business. Business Day, Monday, May, 18.

5. Avolio, B.J. (1999). Full Leadership Development: Building the Vital Forces in Organizations. Thousand Oaks: CA Sage.

6. Bass, B. M. (1990). Bass and Stogdill's Handbook of Leadership: Theory, Research, and Managerial Applications. (3rd ed.). New York: Free Press.

7. Bass, B. M., \& Avolio, B. J. (1997). Full Range Leadership: Manual for the Multifactor Leadership Questionnaire. Palo Alto, CA: Mind Garden.

8. Bass, B. M., \& Avolio, B. J. (1994). Improving organizational Effectiveness through Transformational Leadership. Thousand Oaks, CA: Sage.

9. Bass, B. M. (1985). Leadership and Performance beyond Expectations. New York, Free Press.

10. Boehnke, K., Bontis, N. Distefano, J., \& Distefano, A. (2003). Transformational Leadership: An Examination of Cross-national Differences and Similarities. Leadership and Organization Development Journal, 24(1/2), 5-17.

11. Burns, J. M. (1978). Leadership. New York: Harper \& Row

12. Conger, J.A. (1999). Charismatic \& Transformational Leadership in Organizations: An Insider's Perspective on these Developing Streams of Research. The Leadership Quarterly, 10(2): 45-169.

13. Conger, J.A. \& Kanungo, R.N. (1987). Towards a Behavioral Theory of Charismatic Leadership in Organizational Settings. Academy of Management Review, 12(4), 637-467.

14. Fenwick, F. J. \& Gayle, C. A. (2008). Missing Links in Understanding the Relationship between Leadership and Organizational Performance. International Business \& Economics Research Journal, Volume 7.

15. Fry, L. W. (2003). Towards a Theory of Spiritual Leadership. The Leadership Quarterly, 14, 693-727.

16. Glantz, J. (2002). Finding Your Leadership Style. A Guide for Educators; Association for Supervision and Curriculum Development.

17. Guzzo, R. A. \& Dickson, M. W. (1996). Teams in Organizations. Annual Review of Psychology, 47(1):307-338

18. Humphreys, J. H., \& Einstein, W. O. (2003). Nothing New under the Sun: Transformational Leadership from a Historical Perspective. Management Decision, 41(1/2), 85-95.

19. House, R. J. \& Aditya, R. N. (1997). The Social Scientific Study of Leadership: Quo Vadis? Journal of Management, (23)3: 409-473.

20. Howell, J. M., \& Avolio, B. J. (1992). Transformational Leadership, Transactional Leadership, Locus of Control, and Support for Innovation: Key Predictors of Consolidated-Business-Unit Performance. Journal of Applied Psychology, 78, 891-902.

21. Howell, J., \& Frost, P. (1989). A Laboratory Study of Charismatic Leadership. Journal of Organizational Behaviour and Human Development Processes, Vol 43, 243 - 269.

22. Judge, T. A., Bono, J.E., Ilies, R. and Gerhardt, M.W. (2002). Personality \& leadership: A Qualitative \& Quantitative Review. Journal of Applied Psychology, 87(4): 765-780.

23. Judge, T. A. \& Piccolo, R. F. (2004). Transformational \& Transactional Leadership: A Meta-analytic Test of their Relative Validity. Journal of Applied Psychology, 89(5): 755-768.

24. Judge, T. A. and Ilies, R. (2002). Relationship of Personality to Performance Motivation: A meta-analytic review. Journal of Applied Psychology, 87(4): 797-807.

25. Katz, D., \& St. Kahn, R. L. (1978). The social psychology of organization (2nd ed.). New York:Wiley.

26. Keller, R. T. (2006). Transformational Leadership, Initiating Structure \& Substitutes for Leadership: A Longitudinal Study of Research \& Development Project Team Performance. Journal of Applied Psychology, 91(1): 202-210. 
27. Koontz, H. \& Donnell, C. (1993). Introduction to Management. McGraw-Hill Inc., New York.

28. Lado, A. A., Boyd, N. G. \& Wright, P. (1992). A Competency-based Model of Sustainable Competitive Advantage: Toward a Conceptual Integration. Journal of Management, 18(1): 77-91.

29. Lee and Chuang (2009). The Impact of Leadership Styles on Job Stress and Turnover Intention: Taiwan Insurance Industry as an Example. www.hclee@ttu.edu.tw

30. McGrath, G. R and MacMillan, I. C. (2000). Entrepreneurial Mindset: Strategies for Continuously Creating Opportunity in an Age of Uncertainty. Harvard Business School Press Books.

31. McShane, S. L. and Von Glinow, M. A. (2000). Organizational Behavior. Burr Ridge, IL: Irwin/McGrawHill.

32. Mehra, A., Smith, B., Dixon, A., \& Robertson, B. (2006). Distributed Leadership in Teams: The Network of Leadership Perceptions and Team Performance. Leadership Quarterly, 17: 232-245.

33. Messick, D. M. \& Kramer, R. M. (2004). The Psychology of Leadership: New Perspectives and Research. Lawrence Erlbaum Associates, Publishers. New Jersey.

34. Meyer, G. D. and Heppard, K.A. (2000). Entrepreneurial Strategies: The Dominant Logic of Entrepreneurship. New York, NY: Irwin University Books.

35. Podsakoff, P. M., McKenzie, S. B., \& Bommer, W. H. (1996). Transformational Leader Behavior and Substitutes for Leadership as Determinants of Employee Satisfaction, Commitment, Trust, and Organizational Citizenship Behaviors. Journal of Management, 22(2), 259-298.

36. Purcell, J., Kinnie, N., Hutchinson, S., Rayton, B. \& Swart, J. (2004). Understanding the People \& Performance Link: Unlocking the Black Box. Research Report, Chartered Institute of Personnel and Development.

37. Rowe, W. G. (2001). Creating Wealth in Organizations: The Role of Strategic Leadership. Academy of Management Executive, 15: 81-94.

38. Santora, J. C., Seaton, W. \& Sarros, J. C. (1999). Changing Times: Entrepreneurial Leadership in a Community-based Nonprofit Organization. Journal of Leadership Studies, 6(3-4); $101-109$.

39. Saowalux, P. \& Peng, C. (2007). Impact of Leadership Style on Performance: A Study of Six Sigma Professionals in Thailand. International DSI/Asia and Pacific DSI, July, 2007.

40. SMEDAN. (2008). Small and Medium Enterprises Performance in Nigeria: A report presented at African Entrepreneurship Seminar Organized in Collaboration with the Scientific Committee on Entrepreneurship of the University of Essex. United Kingdom on the 5th of June.

41. Stogdill, R.M. \& Coons, A.E. 1957. Leader Behavior it's Description and Measurement. Ohio: Bureau of Business Research, The Ohio State University, 88, 1-27.

42. Taffinder, P. (2006). Leadership Crash Course: How to Create Personal Leadership Value. $2^{\text {nd }}$ Edition, London; GBR Ltd.

43. Tarabishy, A., Solomon, G., Fernald Jr., L.W. \& Sashkin, M. (2005). The Entrepreneurial Leader's Impact on the Organization's Performance in Dynamic Markets. Journal of Private Equity, 8(4): 20-29.

44. Teece, D.J., Pisano, G. \& Shuen, A. (1997). Dynamic Capabilities \& Strategic Management. Strategic Management Journal, 18(7): 509-533.

45. Unamaka, F. C. (1995). Business Administration in Enugu. Enugu; Precision Printers and Publishers.

46. Venkataraman, S. (1997). The distinctive Domain of Entrepreneurship Research: An Editor's Perspective, in J. Katz \& J. Brodkhaus (eds), Advances in Entrepreneurship, Firm Emergence, and Growth. Greenwich, CT: JAI, Press, 3: 19-38.

47. Yammarino, F. J., Spangler, W. D. \& Bass, B. M. (1993). Transformational Leadership \& Performance: A longitudinal Investigation. The Leadership Quarterly, 4(1): 81-102.

48. Yukl, G. (2002). Leadership in Organizations. 5 rd Edition. Englewood Cliffs, NJ: Prentice-Hall.

49. Zhu, W., Chew, I. K. h. \& Spangler, W. D. (2005). CEO Transformational Leadership \& Organizational Outcomes: The Mediating Role of Human-Capital-Enhancing Human Resource Management. The Leadership Quarterly, 16(1): 39-52. 
Dependent Variable: PSETFLS

\section{APPENDIX \\ E-Views Regression Output}

Method: Least Squares

Date: 24/10/11 Time: 14:29

Sample: 110

Included observations: 10

\begin{tabular}{|c|c|c|c|c|}
\hline Variable & Coefficient & Std. Error & t-Statistic & Prob. \\
\hline $\mathrm{CHM}$ & 0.310436 & 0.237321 & 1.308081 & 0.2387 \\
\hline ISM & -0.216371 & 0.112228 & -1.927967 & 0.1021 \\
\hline ISC & 0.104436 & 0.094359 & 1.106789 & 0.3108 \\
\hline C & 2.766268 & 0.918217 & 3.012650 & 0.0236 \\
\hline R-squared & 0.486445 & Mean dependent var & & 3.520000 \\
\hline Adjusted R-squared & 0.229668 & S.D. dependent var & & 0.113529 \\
\hline S.E. of regression & 0.099643 & Akaike info criterion & & -1.485272 \\
\hline Sum squared resid & 0.059572 & Schwarz criterion & & -1.364238 \\
\hline Log likelihood & 11.42636 & Hannan-Quinn criter. & & -1.618046 \\
\hline F-statistic & 1.894423 & Durbin-Watson stat & & 2.632009 \\
\hline Prob(F-statistic) & 0.231598 & & & \\
\hline
\end{tabular}

Dependent Variable: PSETSLS

Method: Least Squares

Date: 24/10/11 Time: 14:31

Sample: 110

Included observations: 10

\begin{tabular}{|c|c|c|c|c|}
\hline Variable & Coefficient & Std. Error & t-Statistic & Prob. \\
\hline CCR & 0.468510 & 0.071205 & 6.579767 & 0.0003 \\
\hline CME & 0.474654 & 0.034206 & 13.87651 & 0.0000 \\
\hline C & 0.230415 & 0.305741 & 0.753627 & 0.4757 \\
\hline R-squared & 0.968929 & Mean dependent var & & 3.720000 \\
\hline Adjusted R-squared & 0.960051 & S.D. dependent var & & 0.139841 \\
\hline S.E. of regression & 0.027950 & Akaike info criterion & & -4.073457 \\
\hline Sum squared resid & 0.005469 & Schwarz criterion & & -3.982682 \\
\hline Log likelihood & 23.36729 & Hannan-Quinn criter. & & -4.173038 \\
\hline F-statistic & 109.1449 & Durbin-Watson stat & & 1.533773 \\
\hline Prob(F-statistic) & 0.000005 & & & \\
\hline
\end{tabular}

